\title{
Antibodies to inositol 1,4,5-triphosphate receptor 1 in patients with cerebellar disease
}

\section{OPEN}

Penelope Fouka, BSc* Harry Alexopoulos,

DPhil*

Ioanna Chatzi, MD

Skarlatos G. Dedos, PhD Martina Samiotaki, PhD George Panayotou, PhD Panagiotis Politis, $\mathrm{PhD}$

Athanasios Tzioufas, MD

Marinos C. Dalakas, MD, FAAN

Correspondence to Dr. Dalakas: mdalakas@med.uoa.gr

Supplemental data at Neurology.org/nn

\section{ABSTRACT}

Objective: To describe newly identified autoantibodies associated with cerebellar disorders.

Design/Methods: We first screened the sera of 15 patients with cerebellar ataxia, without any known associated autoantibodies, with immunocytochemistry on mouse brain. After characterization and validation of a newly identified antibody, 85 additional patients with suspected autoimmune cerebellar disease were screened using a cell-based assay.

Results: Immunoglobulin G from one of the first 15 patients demonstrated a distinct staining pattern on Purkinje neurons. This autoantibody, as characterized further by immunoprecipitation and mass spectrometry, was binding inositol 1,4,5-triphosphate receptor 1 (IP3R1), an intracellular channel that mediates the release of $\mathrm{Ca}^{2+}$ from intracellular stores. Anti-IP3R1 specificity was then validated with a cell-based assay. On this basis, screening of 85 other patients with cerebellar disease revealed 2 additional IP3R1-positive patients. All 3 patients presented with cerebellar ataxia; the first was eventually diagnosed with primary progressive multiple sclerosis, the second had a homozygous CAG insertion at the gene TBP, and the third was thought to have a neurodegenerative disease.

Conclusions: We independently identified an autoantibody against IP3R1, a protein highly expressed in Purkinje neurons, confirming an earlier report. Because a mouse knockout model for IP3R1 exhibits ataxia and epilepsy, this autoantibody may have a functional role. The heterogeneity of the antibody-positive patients suggests that this antibody may either have a direct involvement in disease pathogenesis or it is a surrogate marker secondary to cerebellar injury. Anti-IP3R1 antibodies should be further explored in various ataxic and epileptic syndromes as they may denote a marker of response to immunotherapies. Neurol Neuroimmunol Neuroinflamm 2017;4:e306; doi: 10.1212/NXI.0000000000000306

\section{GLOSSARY}

BSA = bovine serum albumin; CBA = cell-based assay; IgG = immunoglobulin G; IP3R1 = inositol 1,4,5-triphosphate receptor 1 ; NGS = normal goat serum; PBS = phosphate-buffered saline; PPMS = primary progressive multiple sclerosis; SCA $=$ spinocerebellar ataxia; TTBS $=$ Tris-buffered saline with $0.1 \%$ Tween-20.

Cerebellar disorders may present with a multitude of signs and symptoms including ataxia, dysarthria, dysdiadochokinesia, dysmetria, hypotonia, nystagmus, scanning speech, and tremor. The etiology of cerebellar disorders is diverse and includes immune-mediated mechanisms. More specifically, autoimmune cerebellar symptoms may be associated with antibodies against intracellular targets such as anti-GAD antibodies, ${ }^{1}$ with paraneoplastic cerebellar degeneration associated with antibodies such as anti-Yo, $\mathrm{Hu}$, and $\mathrm{Tr} / \mathrm{DNER},{ }^{2}$ with the cerebellar type of Hashimoto encephalopathy, with ataxia associated with systemic lupus erythematosus, but also with antibodies that target membrane-bound molecules, primarily expressed in the Purkinje neurons, such as Ca/RhoGTPase-activating protein 26 (ARHGAP26) ${ }^{3}$ and mGluR1. ${ }^{4}$ The

\footnotetext{
*These authors contributed equally to this work.

From the Neuroimmunology Unit, Department of Pathophysiology, Faculty of Medicine (P.F., H.A., I.C., A.T., M.C.D.), and Department of Biology (S.G.D.), National and Kapodistrian University of Athens; Department of Molecular Oncology (M.S., G.P.), B.S.R.C. "Alexander Fleming," Athens; and Center of Basic Research (P.P.), Biomedical Research Foundation of the Academy of Athens, Greece.

Funding information and disclosures are provided at the end of the article. Go to Neurology.org/nn for full disclosure forms. The Article Processing charge was paid by Institute of Autoimmune Systemic and Neurological Disorders.

This is an open access article distributed under the terms of the Creative Commons Attribution-NonCommercial-NoDerivatives License 4.0 (CC BY-NC-ND), which permits downloading and sharing the work provided it is properly cited. The work cannot be changed in any way or used commercially without permission from the journal.
} 

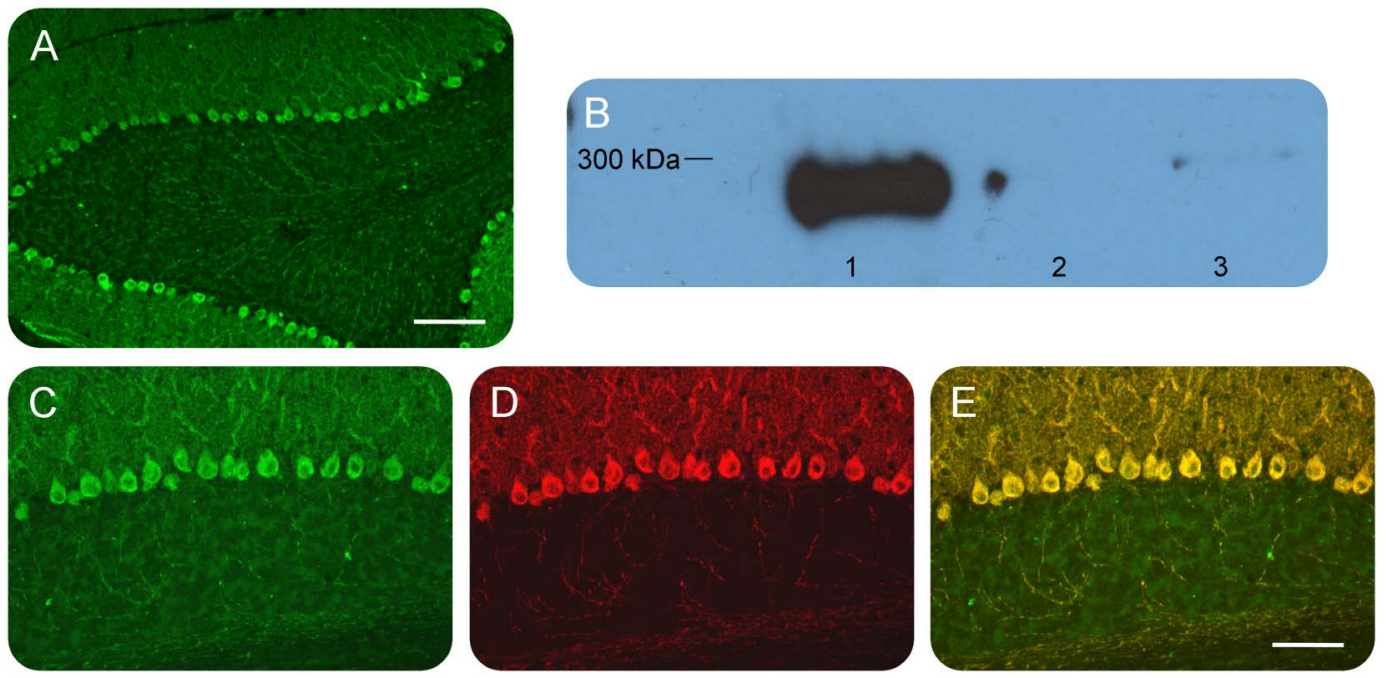

Patient sera with a working diagnosis of cerebellar ataxia were screened using immunohistochemistry in mouse brain slices. A specific pattern was identified, where the antibodies bound primarily the Purkinje cells (A). Following antibody identification, the precipitate used for the mass spectrometry was blotted and probed with a commercial antibody against IP3R1. The antibody recognized the band, with an apparent molecular weight of $270-280 \mathrm{kDa}$ (lane 1). The same antibody did not recognize precipitates from healthy control subjects (lanes 2 and 3) (B). We double-labeled mouse brain with patient serum (C) and the commercial antibody against IP3R1 (D). The colocalization was near perfect, confirming the identity of the autoantibody (E). (A) Scale bar $200 \mu \mathrm{m}$; (C-E) scale bar $100 \mu \mathrm{m}$.

main objective of our study was to identify and describe new autoantibodies associated with cerebellar disorders.

METHODS Patients and standard protocol approvals, registrations, and consents. Patient clinical data and sera were obtained from the records of our neuroimmunology diagnostic service. The Ethics Committee of the University of Athens granted ethical approval for this study.

Tissue immunohistochemistry. Sagittal mouse brain cryostat sections (12 $\mu \mathrm{m}$ thick) were fixed for 5 minutes in cold paraformaldehyde $4 \%$ and permeabilized with Triton $0.3 \%$ in phosphatebuffered saline (PBS). Following PBS washing and 1 hour blocking in $10 \%$ normal goat serum (NGS), the sections were incubated with patient serum (1/50 dilution) or anti- inositol 1,4,5-triphosphate receptor 1 (IP3R1) primary antibody (Thermo PA1-901 rabbit polyclonal antibody, 1/200 dilution; see Results, section regarding IP3R1 identification) in $1 \%$ bovine serum albumin (BSA) for 1 hour. The sections were then incubated with AlexaFluor488 anti-human or AlexaFluor568 anti-rabbit antibodies (Invitrogen, Carlsbad, CA) at $1 / 500$ dilution in $1 \%$ BSA and visualized with a Zeiss (Oberkochen, Germany) fluorescence microscope.

Immunoprecipitation and mass spectrometry. Protein from mouse cerebellae was extracted in lysis buffer containing $25 \mathrm{mM}$ Tris $\mathrm{pH} 7,150 \mathrm{mM} \mathrm{NaCl}, 1 \mathrm{mM}$ EDTA pH 8, 1\% Triton, and protease inhibitors (Sigma, St. Louis, MO). Patient and normal control sera $(70 \mu \mathrm{L})$ were incubated with $3 \mathrm{mg}$ of protein extract overnight at $4^{\circ} \mathrm{C}$. Protein $\mathrm{A} / \mathrm{G}$ agarose beads were added to the supernatants for 3 hours at $4^{\circ} \mathrm{C}$. After washing with lysis buffer, the beads were centrifuged and the pellets were resuspended in $50 \mu \mathrm{L}$ electrophoresis sample buffer, boiled, and centrifuged. Supernatants were separated in a $7 \%$ gel and bands were visualized with Coomassie Brilliant Blue, excised, and analyzed with mass spectrometry.

Western blot. Following mass spectrometry, the same supernatants were again separated in a 7\% gel and the proteins were blotted into nitrocellulose. The membrane was blocked with 5\% nonfat milk in Tris-buffered saline with $0.1 \%$ Tween-20 (TTBS) for 1 hour and incubated with the anti-IP3R1 antibody (1/1,000 dilution) in $0.5 \%$ nonfat milk in TTBS overnight at $4^{\circ} \mathrm{C}$. Following TTBS washes, the membrane was incubated with a secondary goat anti-human HRP-conjugated antibody (1/2,000 dilution) and the protein bands were visualized with a Pierce (Rockford, IL) enhanced chemiluminescence Western blotting substrate.

Cell based assays. HEK293T cells were transfected (Xfect; Clontech, Mountain View, CA) with pcDNA3.2-Venus-rIP3R1 clone (see e-Methods at Neurology.org/nn). The cells were then fixed for 5 minutes in cold acetone and after PBS washing they were incubated in $10 \%$ NGS for 1 hour. The cells were then incubated with patient serum (1/25 dilution) or anti-IP3R1 (1/2,000 dilution) in 1\% BSA for 2 hours. After extensive washes, the cells were incubated with AlexaFluor 568 anti-human or anti-rabbit antibody, respectively, at 1/750 dilution in $1 \%$ BSA. Cells were visualized with a Zeiss fluorescence microscope.

RESULTS Antigen identification. We initially screened 15 patients with cerebellar ataxia and no anti-GAD or anti-Yo antibodies (determined with commercially available ELISA and Western blot kits, respectively), with immunohistochemistry on mouse brain slices. In one patient (index patient), we observed a specific pattern of staining (figure 1A) where the autoantibodies bound Purkinje neurons. ${ }^{5}$ On this basis, we set out to identify and characterize 

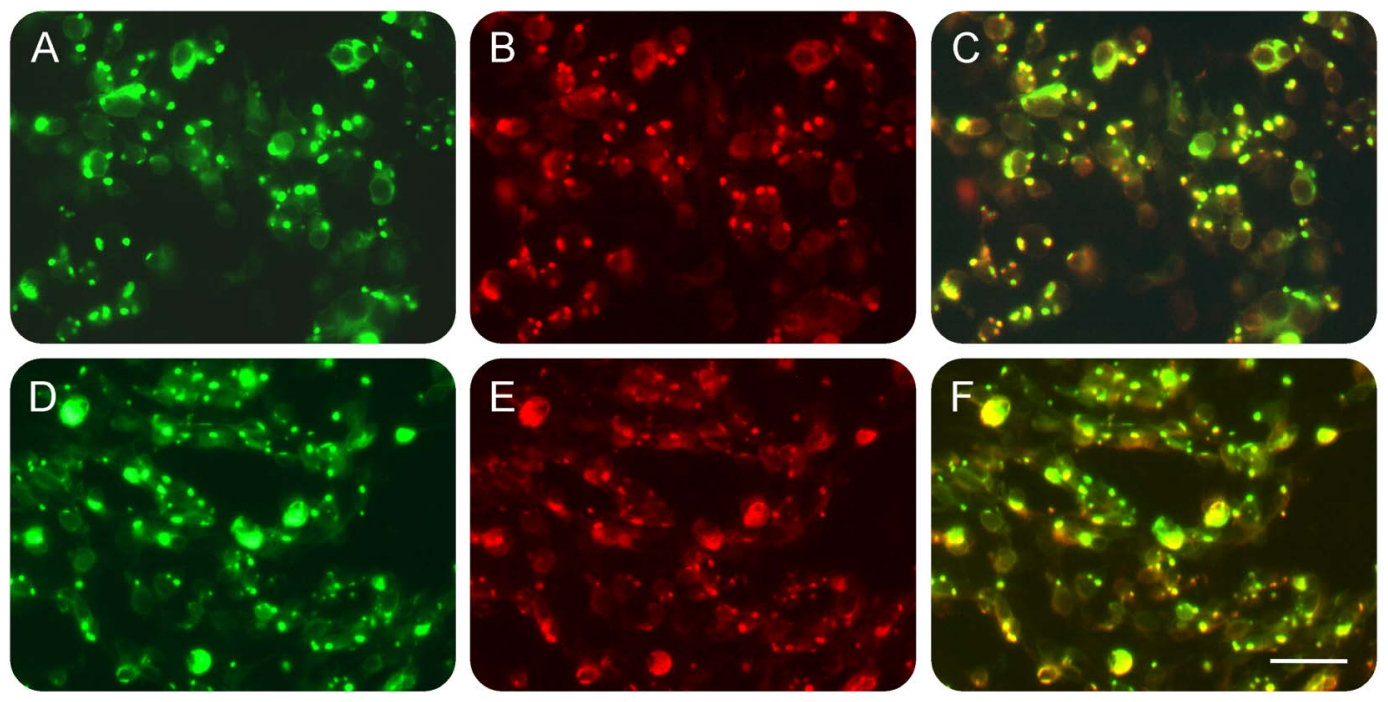

The full-length inositol 1,4,5-triphosphate receptor 1 (IR3R1) clone tagged with YFP was expressed in HEK293 cells (A, D). The cells were incubated with either a commercial antibody against IP3R1 (B) or with patient serum (E). Merged images (C, F) show that the CBA assay is sensitive and can detect IP3R1 serum antibodies. Scale bar $75 \mu \mathrm{m}$.

the antibodies corresponding to the specific pattern. Following immunoprecipitation and electrophoresis, a single protein band was excised from a sodium dodecyl sulfate polyacrylamide gel electrophoresis gel and sent for mass spectrometry. The antigen was identified as the inositol 1,4,5-triphosphate receptor 1 (IP3R1). Subsequently, the identity of the antibody was confirmed, first by staining the precipitating band with a commercial antibody against the IP3R1 receptor (figure 1C) and then by double-staining mouse brain slices with patient serum and the commercial antiIP3R1 antibody. A near-perfect tissue colocalization was observed (figure 1, D and E).

Clinical associations. To validate our finding, sera from 85 patients referred to our neuroimmunology laboratory with cerebellar signs or symptoms were tested with the more sensitive and specific method of cellbased assay (CBA). For the screening, IP3R1 tagged with YFP was expressed in HEK293 cells (figure 2). Three patients (index patient plus 2 new patients) were found positive for IP3R1 antibodies. No CSF was available for testing. Their pertinent clinical data based on the record review and clinical re-evaluation (2/3 patients) are as follows.

Patient 1: Index patient. A 41-year-old man was admitted to the hospital because of gait imbalance and walking impairment that started subacutely 3 months prior to admission. A brain MRI revealed diffuse nonenhancing demyelinating lesions consistent with multiple sclerosis (figure e-1, A-C). CSF showed oligoclonal immunoglobulin $\mathrm{G}$ ( $\operatorname{IgG}$ ) bands and elevated $\mathrm{IgG}$ index. During a 4-year follow-up period, his symptoms continued to progress, with prominent cerebellar signs including gait ataxia, wide-based gait, horizontal nystagmus, and bilateral intention tremor. A follow-up MRI was unchanged. The findings were consistent with primary progressive multiple sclerosis (PPMS). During the course of his disease, the patient has been treated with steroids, glatiramer acetate, and interferon- $\beta-1 \mathrm{a}$, none of which has been convincingly beneficial.

Patient 2. A 42-year-old woman presented with subacute onset of walking instability and a broadbased gait that necessitated help for support. There was horizontal nystagmus at extreme lateral gaze ipsilaterally, dysarthria, dysmetria, and dysdiadochokinesis of upper limbs. Deep tendon reflexes were equally elicited throughout; muscle strength was $5 / 5$ in all 4 extremities and sensory examination results were normal. She had symptoms of dysautonomia. MRI revealed a small degree of cerebellar atrophy. CSF analysis revealed no signs of inflammation (IgG index normal, no oligoclonal bands). Genetic testing revealed a single homozygous CAG insertion at the TBP gene (TATA-binding protein). No cancer has been identified.

Patient 3. A 79-year-old woman reported subacute onset of walking instability and the need for walking aids (based on a telephone interview and medical records review). She had ataxia in both upper and lower limps, dysarthria, dysautonomia (orthostatic hypotension), and REM sleep disturbances. Her muscle strength was normal, without any cognitive deficits or visual disturbances. Her brain MRI showed multiple lesions of ischemic origin (figure e-1, D-F). Her symptoms are consistent with neurodegenerative disease in the form of multiple system atrophy. No cancer 
has been identified and CSF was not available for testing.

Other immune disease controls. Because in a previous study $^{6}$ it was shown that $48.6 \%(17 / 35)$ of patients with primary Sjögren syndrome harbored antibodies against IP3R1, we assayed 45 patients with primary Sjögren syndrome with our specific CBA; they were all negative. This discrepancy is likely attributed to different specificity and sensitivity of the methods used or possibly to the difference of diagnostic criteria used in defining disease among the examined patients. Since 1 of our 3 positive patients had a working diagnosis of PPMS, we screened 15 additional patients with PPMS, 5 patients with anti-GAD $(+)$ cerebellar ataxia, and 15 healthy controls by CBA. All patients and controls were also negative.

DISCUSSION We report 3 patients positive for an antibody against IP3R1, a ligand-gated nonselective cation channel activated by inositol 1,4,5-triphosphate. IP3R1 is localized in the smooth endoplasmic reticulum and triggers $\mathrm{Ca}^{++}$release downstream of mGluR1 stimulation and after direct interaction with the Homer proteins, including Homer3. ${ }^{7}$ During the course of clinical characterization of our patients, Jarius et al. ${ }^{8}$ reported this antibody in patients with suspected cerebellar disease. As discussed in a recent review article, ${ }^{9}$ this antibody appears to be fairly common among other anti-Purkinje neuron autoantibodies, but its clinical significance remains unexplored.

Mutations in the IP3R1 genes have been implicated in spinocerebellar ataxia (SCA) 15 and SCA16. ${ }^{10,11}$ In addition, a mouse knockout model for IP3R1 exhibits ataxia and epilepsy, signifying a functional role of this protein and a clinical connection with various ataxic and epileptic syndromes. ${ }^{12}$ Recent evidence suggest that many proteins, including IP3R1, implicated in cellular $\mathrm{Ca}^{++}$regulation are targets of autoimmunity and comprise the same pathways affected by the genetic variants of cerebellar disease. All our reported patients had a predominant cerebellar disease, even though their causes were diverse, including PPMS, genetic, or possibly neurodegenerative.

Although the presence of this antibody suggests a coexisting autoimmunity, a pathogenetic role is ambiguous considering the intracellular localization of the antigen. More often it is antibodies that can directly access antigens localized on the cell surface that have a direct pathogenetic role, e.g., anti-NMDAR or antiAQP4 antibodies. Whether these antibodies may be also produced intrathecally or circulate in the CSF is unknown, because we had no access to CSF samples. In some autoimmune neurologic diseases, such as NMDA receptor encephalitis, the antibodies in the CSF are pathogenic, but in others, such as aquaporin4-positive neuromyelitis optica, serum antibodies are pathogenic but they are not present in the CSF. Therefore, their absence in the CSF does not preclude pathogenicity. Because the cerebellum was not primarily affected, as depicted in the MRI (figure e-1), the possibility that the antibodies may have been derived from a widespread structural damage cannot be excluded.

It remains to be determined whether these antibodies are pathogenic, biomarkers, or simply surrogate markers. Given the heterogeneity of the underlying diseases and their reported (though unconfirmed) presence in Sjögren syndrome, the clinical utility of these antibodies remains unclear. Whether anti-IP3R1 autoimmunity follows a degenerative cerebellar process that generates release of neoantigens or these antibodies are produced de novo remains unknown. Functional experiments are required to explore their pathogenic role, if any. In spite of these uncertainties, anti-IP3R1 antibodies might be markers of potentially treatable autoimmune forms of cerebellar disease.

\section{AUTHOR CONTRIBUTIONS}

Dr. Alexopoulos, Dr. Dalakas: study concept and design. P. Fouka, Dr. Alexopoulos, Dr. Chatzi, Dr. Samiotaki: acquisition of data. Dr. Dedos: Provision of materials. P. Fouka, Dr. Alexopoulos, Dr. Dedos, Dr. Samiotaki, Dr. Panayotou, Dr. Politis, Dr. Tzioufas: data analysis and interpretation. Dr. Alexopoulos, Dr. Dedos, Dr. Dalakas: drafting and critical revision of the manuscript.

\section{STUDY FUNDING}

This study was funded by the Special Research Account of the University of Athens and the Institute of Autoimmune Systemic and Neurological Disorders.

\section{DISCLOSURES}

P. Fouka reports no disclosures. H. Alexopoulos is on the editorial board for Journal of Autoimmunity. I. Chatzi reports no disclosures. S.G. Dedos received research support from National and Kapodistian University of Athens. M. Samiotaki reports no disclosures. G. Panayotou served on the editorial board for Biochemical Journal and Journal of Proteomics; holds a patent for Polypeptides having kinase activity, their preparation and use, methods to inhibit serine kinase activity, and to alter intersubunit binding activity of phosphatidylinositol 3-kinase, and serine kinase active sequence of the same; and received research support from General Secretariat of Research \& Technology. P. Politis received research support from Greek Ministry of Education. A. Tzioufas reports no disclosures. M. Dalakas serves on the CIDP steering committee for Novartis and on DSMB for Baxalta; received travel funding and/or speaker honoraria from Baxter, CSL, Servier, Novartis, Hoffman LaRoche, and Merck/Serono; served on the editorial board for Neurology ${ }^{\circledR}$, BMC Neurology, Acta Myologica, and Acta Neurologica Scandinavica; was an associate editor for Therapeutic Advances in Neurology; consulted for Therapath, Grifols, Novartis, Baxter, Octapharma, Hoffman LaRoche, and CSL; and received institutional support to Thomas Jefferson University and/or University of Athens Medical School from Merck Serono, Genzyme, Novartis, Guillain-Barre/CIDP Foundation, Dysimmune Diseases Foundation, CSL, Biogen, and Newfactor. Go to Neurology.org/nn for full disclosure forms.

Received June 6, 2016. Accepted in final form October 10, 2016.

\section{REFERENCES}

1. Rakocevic G, Raju R, Semino-Mora C, Dalakas MC. Stiff person syndrome with cerebellar disease and high-titer anti-GAD antibodies. Neurology 2006;67:1068-1070. 
2. Shams'ili S, Grefkens J, de Leeuw B, et al. Paraneoplastic cerebellar degeneration associated with antineuronal antibodies: analysis of 50 patients. Brain 2003;126: 1409-1418.

3. Jarius $\mathrm{S}$, Martinez-Garcia P, Hernandez AL, et al. Two new cases of anti-Ca (anti-ARHGAP26/GRAF) autoantibodyassociated cerebellar ataxia. J Neuroinflammation 2013;10:7.

4. Lopez-Chiriboga AS, Komorowski L, Kumpfel T, et al. Metabotropic glutamate receptor type 1 autoimmunity: clinical features and treatment outcomes. Neurology 2016;86:1009-1013.

5. Alexopoulos H, Chatzi I, Fouka P, et al. Investigating novel autoantibodies in CNS demyelinating diseases. J Neuroimmunology 2012;253:8-9.

6. Miyachi K, Iwai M, Asada K, Saito I, Hankins R, Mikoshiba K. Inositol 1,4,5-trisphosphate receptors are autoantibody target antigens in patients with Sjogren's syndrome and other systemic rheumatic diseases. Mod Rheumatol 2007;17:137-143.
7. Nakanishi S. Synaptic mechanisms of the cerebellar cortical network. Trends Neurosci 2005;28:93-100.

8. Jarius S, Scharf M, Begemann N, et al. Antibodies to the inositol 1,4,5-trisphosphate receptor type 1 (ITPR1) in cerebellar ataxia. J Neuroinflammation 2014;11:206.

9. Jarius S, Wildemann B. "Medusa head ataxia": the expanding spectrum of Purkinje cell antibodies in autoimmune cerebellar ataxia. Part 3: anti-Yo/CDR2, anti-Nb/AP3B2, PCA-2, anti-Tr/DNER, other antibodies, diagnostic pitfalls, summary and outlook. J Neuroinflammation 2015;12:168.

10. van de Leemput J, Chandran J, Knight MA, et al. Deletion at ITPR1 underlies ataxia in mice and spinocerebellar ataxia 15 in humans. PLoS Genet 2007;3:e108.

11. Marelli C, van de Leemput J, Johnson JO, et al. SCA15 due to large ITPR1 deletions in a cohort of 333 white families with dominant ataxia. Arch Neurol 2011;68:637-643.

12. Matsumoto $M$, Nakagawa $T$, Inoue $T$, et al. Ataxia and epileptic seizures in mice lacking type 1 inositol 1,4,5-trisphosphate receptor. Nature 1996;379:168-171. 


\section{Neurology \\ Neuroimmunology \& Neuroinflammation}

\section{Antibodies to inositol 1,4,5-triphosphate receptor 1 in patients with cerebellar disease Penelope Fouka, Harry Alexopoulos, Ioanna Chatzi, et al. \\ Neurol Neuroimmunol Neuroinflamm 2017;4; \\ DOI 10.1212/NXI.0000000000000306}

This information is current as of December 5, 2016

\section{Updated Information \& Services \\ Supplementary Material}

References

Subspecialty Collections

Permissions \& Licensing

Reprints including high resolution figures, can be found at: http://nn.neurology.org/content/4/1/e306.full.html

Supplementary material can be found at: http://nn.neurology.org/content/suppl/2016/12/05/4.1.e306.DC1

This article cites 12 articles, 0 of which you can access for free at: http://nn.neurology.org/content/4/1/e306.full.html\#\#ref-list-1

This article, along with others on similar topics, appears in the following collection(s):

Autoimmune diseases

http://nn.neurology.org//cgi/collection/autoimmune_diseases

Gait disorders/ataxia

http://nn.neurology.org//cgi/collection/gait_disorders_ataxia

Information about reproducing this article in parts (figures,tables) or in its entirety can be found online at:

http://nn.neurology.org/misc/about.xhtml\#permissions

Information about ordering reprints can be found online:

http://nn.neurology.org/misc/addir.xhtml\#reprintsus

Neurol Neuroimmunol Neuroinflamm is an official journal of the American Academy of Neurology.

Published since April 2014, it is an open-access, online-only, continuous publication journal. Copyright

Copyright (C) 2016 The Author(s). Published by Wolters Kluwer Health, Inc. on behalf of the American

Academy of Neurology. All rights reserved. Online ISSN: 2332-7812.

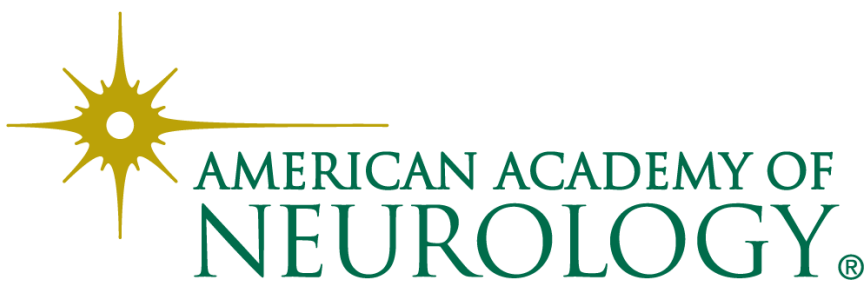

